\title{
LA HISTORIA Y DIDÁCTICA DE LAS MATEMÁTICAS: UM ENCUENTRO POSIBLE
}

\author{
Edilene Simões Costa dos Santos ${ }^{1}$ \\ edilenesc@gmail.com \\ Cristiano Alberto Muniz ${ }^{2}$ \\ cristianoamuniz@gmail.com \\ Maria Terezinha Jesus Gaspar ${ }^{2}$ \\ mtjg.gaspar@gmail.com \\ ${ }^{1}$ Universidade Federal de Mato Grosso do Sul \\ ${ }^{2}$ Universidade de Brasília
}

Recibido: 11/11/2019 Aceptado: 22/01/2020

\begin{abstract}
Resumen
Este estudio aborda el valor didáctico de la historia de las matemáticas en la educación matemática, buscando resaltar una posible relación entre la historia y la didáctica de las matemáticas. La investigación analizó la enseñanza-aprendizaje utilizando la historia de las matemáticas en la concepción de producir y sistematizar circunstancias del concepto de área como cantidad autónoma y procedimientos para su medición. La realización de la propuesta de trabajo se realizó a través de la organización, aplicación y análisis de la secuencia didáctica realizada en dos clases de quinto grado, en dos escuelas públicas del Distrito Federal-Brasil. Las conclusiones de esta investigación se centran en el análisis de los procedimientos, dificultades, representaciones, movilización de teoremas y conceptos en acción presentados por los estudiantes que participan en el estudio. A través de los análisis, encontramos el crecimiento gradual del estudiante en la construcción y el significado del concepto del área y su medición, y en la comprensión del conocimiento no está listo y se construye en un proceso que involucra tiempo, conocimiento, contextos y personas. Además, a través del análisis basado en la teoría de los campos conceptuales, fue posible afirmar que los estudiantes demostraron identificar el área como magnitud, en las decisiones de resolución no confundieron superficie con su área ni área con numero
\end{abstract}

Palabras clave: Área, Historia de las matemáticas, Teoría de los Campos Conceptuales

\section{THE HISTORY AND TEACHING OF MATHEMATICS: A POSSIBLE MEETING}

\begin{abstract}
This study approaches the didactic value of the history of mathematics in mathematics education, seeking to highlight a possible relationship between history and didactics of mathematics. The research analyzed teaching-learning using history of mathematics in the conception of circumstances that produce and systematize area concept as autonomous quantity and procedures for its measurement. The realization of the work proposal occurred through organization, application and analysis of a didactic sequence conducted in two fifth grade classes in two public schools in Federal District - Brazil. The conclusions of this investigation focus on the analysis of procedures, difficulties, representations, and mobilization of theorems and concepts in action presented by the students participating in the study. Through the analyzes we found the student's gradual growth in construction and
\end{abstract}


signification of area concept and its measure and in understanding that knowledge is not ready, but it's built in a process that involves time, knowledge, contexts and people. It was also possible, through analysis based on the theory of conceptual fields, to state that students demonstrated to identify area as magnitude, and in decisions for resolution they did not confuse surface with its area nor area with number.

Keywords: Area, History of Mathematics, Theory of conceptual fields

\title{
A HISTÓRIA E A DIDÁTICA DA MATEMÁTICA: UM ENCONTRO POSSÍVEL
}

\begin{abstract}
Resumo
O presente estudo aborda o valor didático da História da Matemática na educação matemática, analisando o ensino-aprendizagem ao se utilizar a história da matemática na concepção de circunstâncias produtoras e sistematizadoras do conceito de área como grandeza autônoma e procedimentos para sua medida. A efetivação da proposta do trabalho ocorreu por meio da organização, aplicação e análise de sequência didática realizada em duas turmas de quinto ano do Ensino Fundamental, em duas escolas da rede de ensino público do Distrito Federal-Brasil. As conclusões desta investigação centram-se na análise acerca dos procedimentos, dificuldades, representações, mobilização de teoremas e conceitos em ação apresentados pelos alunos participantes do estudo. Por meio dessa análise, constatamos o crescimento gradativo dos alunos na construção e significação do conceito de área e sua medida, além da compreensão de que os conhecimentos não estão prontos, sendo construídos em processo que envolve tempo, conhecimentos, contextos e pessoas. Assim, tendo por base a teoria dos campos conceituais, foi possível afirmar que os alunos demonstraram identificar área como grandeza nas decisões para resolução, não confundindo superfície com sua área e nem área com número.
\end{abstract}

Palavras-chave: Área, História da matemática, Teoria dos Campos Conceituais,

\section{Introdução}

Nas últimas décadas foi desenvolvida uma grande quantidade de estudos e discussões em torno de questões que envolvem o como ensinar matemática para crianças e jovens. Entre as muitas reflexões didático-metodológicas, está a História da Matemática. No entanto, a mesma não tem sido muito usada pelo professor em sala de aula como um instrumento para o ensino e aprendizagem de conceitos matemáticos. Quando muito, ela é um elemento para introduzir um conteúdo, sem muitas implicações pedagógicas.

Ao se pensar mais especificamente nos anos iniciais, a situação torna-se mais complexa, talvez por insegurança metodológica ou epistemológica, mas, reconhecendo o valor histórico do conhecimento matemático e fundamentando-se no valor da narrativa no aprendizado da criança, professores dos anos iniciais tentam inserir a história em suas aulas por meio do que os autores chamam de anedotas ou como elemento motivador que assume a função de apenas introduzir um assunto desconectado com as demais etapas da organização para o desenvolvimento de tal conteúdo.

Outra questão emergente é que o ensino, mesmo dentro da perspectiva histórica, não deve ser pautado na linearidade e na hierarquização dos conteúdos, pois o desenvolvimento cognitivo e a aprendizagem escolar são socioculturalmente influenciados 
pelas representações hegemônicas das ideias, e não necessariamente por todas as representações históricas da mesma. Por exemplo, Vergnaud (1996) pondera que a conceitualização do sujeito pode estabelecer desvios que fazem com que o desenvolvimento não seja na mesma linha lógica da história da civilização, a criança que aprende sendo um sujeito ativo com vivência em um mundo tecnológico e globalizado. Isso nos leva a considerar a importância do ensino e da aprendizagem de conhecimentos matemáticos por meio da História da Matemática como instrumento didático, tendo a compreensão de que o raciocínio do jovem aprendiz pode não acompanhar a linearidade da solução da construção da história do Homem.

Nesse sentido, realizamos uma pesquisa para verificar se alunos dos anos iniciais constroem conhecimentos quando utilizamos a História da Matemática como agente de cognição. O resultado da pesquisa apontou que alunos do Ensino Fundamental podem construir conceitos matemáticos quando inseridos em contextos históricos matemáticos, de forma implícita ou não para eles. Para tal, optamos por trabalhar com o conceito de área e os procedimentos para sua medida e, então, foi elaborada e aplicada, em duas turmas de quinto ano da rede pública de ensino do Distrito Federal, uma sequência de atividades fundamentadas em contextos históricos da matemática e, para verificar se realmente os alunos estavam construindo o conceito de área, utilizadas a Teoria dos Campos Conceituais e a Teoria dos Registros de Representações Semiótica.

\section{Contribuições de Vergnaud e Duval}

A construção do conceito pelo aluno requer a criação de um espaço de ensino e aprendizagem impregnado pela atividade, exploração, investigação, mobilizando-o para a ação. Então, aprender torna-se significativo, onde errar é levado em conta como parte do processo cognitivo. De acordo com Vergnaud (1996, p. 190), esse espaço que ativa o realizar procedimentos de aprendizagem são as situações-problema: "um conceito não assume a sua significação em uma única classe de situações, e uma situação não se analisa com o auxílio de um único conceito", ou seja, são as situações que dão sentido ao conceito, sendo elas as referências no processo de conceitualização. As atividades constituíram-se nesse espaço onde os alunos resolviam as situações-problemas.

Uma vez elaboradas as atividades questionamos: como verificar se o aluno construiu o conceito? Como analisar seus procedimentos para ao final afirmarmos que por meio da história ele constrói conhecimentos?

A Teoria dos Campos Conceituais de Vergnaud (1990, 1996, 2003) nos auxiliou 
nas análises a fim de responder nossa questão quanto à construção do conhecimento, à apropriação do saber do tema em estudo por meio da História da Matemática.

Nessa perspectiva, as atividades desenvolvidas pelos alunos, bem como as observações feitas em sala de aula, as entrevistas com os estudantes, os encontros de estudo e planejamento com as professoras foram analisados com base na Teoria dos Campos Conceituais. Além disso, apoiamo-nos em Duval (1994, 2003), acerca do desenvolvimento do pensamento matemático, quando considera que as representações semióticas produzidas pelos sujeitos, além de exteriorizar as suas representações mentais são igualmente fundamentais para as atividades cognitivas do pensamento.

Vergnaud (1996) define que os invariantes operatórios são teoremas em ação e conceitos em ação constituem a base conceitual implícita que permite obter a informação pertinente e, a partir dela e dos objetivos a alcançar, inferir as regras de ação mais pertinentes. Assim, é nos esquemas que devemos pesquisar os conhecimentos em ação do sujeito - os teoremas em ação e os conceitos em ação. É nas situações que ocorre a operacionalidade dos conceitos. O esquema é um referente do sujeito e a situação é a circunstância e o contexto em que o objeto a ele se apresenta e repousa sobre uma conceitualização implícita.

Os conceitos em ação são relacionados a objetos, predicados, classes, condições. Dentro de uma vasta quantidade de conceitos que podem estar disponíveis no repertório dos sujeitos, é selecionada uma pequena parte para cada ação. Os teoremas em ação são proposições, que podem ser verdadeiras ou falsas. Os conceitos em ação se articulam por meio dos teoremas em ação. Portanto, os conceitos em ação e os teoremas em ação podem ser adequados ou não para uma dada classe de situações e permanecem implícitos na ação do sujeito, podendo tornar-se explícitos. (Vergnaud, 1998).

Então, é importante propor situações de desestabilização, no caso, fundamentadas na concepção histórica da matemática. Tais situações tinham como função provocar ações de atividade no sujeito nas quais ele organizava o pensamento para a resolução e, a partir de um esquema, construía novos esquemas. O sujeito só constrói novos esquemas, se os mobilizados por ele não dão conta de obter uma resposta desejável, o que o desestabiliza, levando-o a novos investimentos. Assim, a situação é para o sujeito e o conceito é aquilo de que ele se apropria e o qual reelabora, para dar conta de novas situações, realizando uma síntese de conceitos anteriores de forma racional e criativa.

Vergnaud (1996) esclarece que o sentido de um conceito está fortemente associado à ação de resolução de problemas. Para Duval (1993), a compreensão da aprendizagem da 
matemática pelo sujeito deve levar em conta os conteúdos matemáticos e o funcionamento cognitivo do aluno, observando suas produções e buscando um modelo que seja pertinente para analisar e interpretar tais produções. A teoria de Vergnaud nos orientou nas análises das relações advindas e ocasionadas pelo conceito, enquanto a de Duval norteou as análises das representações dos objetos matemáticos. Nessa perspectiva, consideramos a construção do conceito de área pelo aluno, ou seja, não o conceito pronto expresso em uma definição explicitada no livro didático ou pela professora, mas uma ação experenciada e reelaborada pelo aluno.

Ainda, segundo Duval (2003), um registro de representação semiótica é um sistema de signos que tem por objetivo três funções: a comunicação, o tratamento da informação e a objetivação. Assim sendo, as representações semióticas não cumprem somente o papel de comunicar, elas são igualmente fundamentais para as atividades cognitivas do pensamento. Para esse autor, o objeto matemático em estudo não deve ser confundido com suas representações, e sim reconhecido em cada uma delas. Logo, reconhecemos os registros de representação semiótica como um modelo pertinente para interpretarmos e analisarmos as relações entre as ideias e a produção do conceito de área pelos alunos inseridos em situações elaboradas diante da concepção histórica de tal conhecimento.

As produções externas dos educandos podem nos explicitar as condições de aquisição do conhecimento matemático em questão, isto é, as condições específicas de acesso ou não a tais objetos matemáticos. Ao desenvolver situações diversas, que trazem informações em diferentes linguagens, o aluno procura traduzi-las naquelas que consegue utilizar como uma ferramenta de tratamento da situação. Como cada linguagem traduz algumas propriedades do objeto, mas não todas, uma linguagem pode ser mais adequada que outra para lidar com esse objeto, em uma situação específica. Dessa forma, o conhecimento dos alunos sobre os objetos e suas propriedades é ampliado por meio do trânsito entre representações expressas em diferentes linguagens, as quais se tornam ferramentas para o pensamento no desenvolvimento de situações nas quais esses alunos podem ser inseridos.

Temos, em Duval (2003), que o acesso aos objetos matemáticos ocorre por meio das representações semióticas, pois nem toda operação cognitiva é perceptível ou observável por meio de objetos concretos, ou seja, os conceitos e conteúdos são abstrações desencadeadas por processos de generalização, que necessitam das representações semióticas para que ocorra uma verdadeira apreensão e evolução do pensamento matemático. As representações semióticas das pessoas são externas e conscientes, 
desempenhando o papel de comunicar, exteriorizar as representações mentais, a fim de torná-las acessíveis às outras pessoas, bem como possibilitar o acesso e a comunicação do objeto matemático.

Nas representações semióticas, segundo Duval (2003), dois aspectos devem ser tomados em consideração: a forma, que é o representante, e o conteúdo, o representado. Como existem diferentes registros de representação para o mesmo objeto matemático, a forma pode ser alterada de acordo com os diferentes tipos de tratamento. Assim: "A compreensão (integral) de um conteúdo conceitual repousa sobre a coordenação de ao menos dois registros de representação e esta coordenação manifesta-se pela rapidez e espontaneidade da atividade cognitiva de conversão" (Duval, 1993, p. 51). A coordenação entre dois registros quaisquer se dá por meio de duas operações: conversão e tratamento; então, a formação de uma representação significa uma operação cognitiva.

Nesse sentido, as representações semióticas cumprem várias funções primordiais, tais como a comunicação - para tornar visíveis e acessíveis as representações mentais que dependem da interiorização das representações semióticas - na realização de diferentes funções cognitivas, como objetivação (expressão interna, que se presta ao entendimento particular), tratamento e convenção. (Duval, 1993).

Em algumas das atividades trabalhamos com interpretações autônomas de figuras. Para essas interpretações, Duval (1994) considera quatro tipos de apreensões:

a) sequencial: é solicitada nas tarefas de construção ou nas tarefas de descrição com objetivo de reproduzir uma figura;

b) perceptiva: é a interpretação das formas da figura em uma situação geométrica;

c) discursiva: é a interpretação dos elementos da figura geométrica, privilegiando a articulação dos enunciados;

d) operatória: é uma apreensão centrada sobre as modificações possíveis de uma figura de partida e a reorganização perceptiva que essas modificações sugerem.

Nas atividades os alunos trabalharam com todas as apreensões. A tomada de consciência da distinção das formas de apreensão depende da exigência de resolução da situação na qual o aluno foi inserido.

Ainda de acordo com Duval (1994), a apreensão operatória das figuras depende das modificações pelas quais elas passam. Esse autor classifica essas modificações em:

a) modificação mereológica: a figura pode separar-se em partes que são subfiguras, obtidas a partir da figura dada, fracionando-se e reagrupando-se, isto é, uma relação da parte e do todo; 
b) modificação ótica: a figura pode ser aumentada, diminuída ou deformada - esta modificação transforma uma figura em outra chamada de sua imagem;

c) modificação posicional: é o deslocamento em relação a um referencial - a figura pode ser deslocada ou rotacionada em relação ao referencial.

Tais modificações são realizadas psiquicamente, mentalmente e graficamente. Em nosso trabalho, essas modificações, em sua maioria, ocorreram nas atividades de recorte e de colagem das figuras e também por meio de desenhos. Queremos enfatizar a modificação mereológica por possibilitar o uso da operação de reconfiguração que consiste em organizar uma ou várias subfiguras diferentes de uma figura dada em outra figura. Essa operação permitiu a articulação entre tratamentos, tais como as medidas de áreas por soma de partes elementares, ou evidenciar a equivalência entre as áreas das figuras.

Dessa forma, a História da Matemática tem papel de problematização na perspectiva epistemológica do conhecimento matemático. Nesse contexto, assumimos que o aluno, primeiramente, necessita construir área como grandeza autônoma, distinguindo área e superfície, assim como área e medida da área. Então, para estruturamos a ordem de aplicação das atividades, tomou-se como referência o trabalho desenvolvido por Douady e Perrin-Glorian (1989), que distingue três pontos na aprendizagem de área:

1) Construir a noção de área como grandeza autônoma pela comparação direta de duas superfícies por inclusão ou indireta por recorte e colagem:

a) por comparação direta de superfícies, por meio da inclusão, ou indiretamente, por recorte e colagem, ou seja, cortando uma superfície S, em um número finito de peças, que, depois, são coladas juntas, sem sobreposição. Uma nova superfície S que substitui a S para comparação.

b) por meio da atribuição de uma série de medidas de área (da mesma superfície) usando pedras de pavimentação (figuras) de várias formas.

Isso nos leva a:

i) diferenciar a forma da área de superfície: duas superfícies de formas diferentes podem ter áreas iguais;

ii) distinguir a área de número, enquanto controla a correspondência entre a medida da área de superfícies e números: a área de uma mesma superfície pode corresponder a números diferentes, dependendo da unidade escolhida, mas a área em si não muda. 
2) Estender a aplicação de medida às áreas de superfícies que não podem ser recobertas por quadrados de medida de área unitária, ou seja, por quadrados de lado iguais a uma unidade.

3) Apontar as diferenças entre comprimentos e área.

A seguir exibimos uma relação das atividades que compõem a sequência:

\section{Quadro 1 - Sequência de atividades}

\begin{tabular}{|c|c|c|}
\hline Atividade & Eixo & Objetivo \\
\hline 1 & $\begin{array}{l}\text { Eixo 1: comparação direta de } \\
\text { superfícies por meio da } \\
\text { inclusão. }\end{array}$ & $\begin{array}{l}\text { Perceber que, se uma figura }(*) \text { está contida na outra por } \\
\text { isometria, então a área da primeira é menor do que a área da } \\
\text { segunda. }\end{array}$ \\
\hline 2 & $\begin{array}{l}\text { Eixo 1: comparação direta de } \\
\text { superfícies por meio da } \\
\text { inclusão. }\end{array}$ & $\begin{array}{l}\text { Perceber que, se uma figura é obtida de outra, retirando } \\
\text { parte da primeira, a segunda está contida na primeira e a } \\
\text { área da segunda é menor do que a área da primeira. }\end{array}$ \\
\hline 3 & $\begin{array}{l}\text { Eixo 1: comparação direta de } \\
\text { superfícies por meio da } \\
\text { inclusão. }\end{array}$ & $\begin{array}{l}\text { Comparar as áreas de um conjunto de figuras e colocá-las } \\
\text { em ordem crescente da área. }\end{array}$ \\
\hline 4 & $\begin{array}{l}\text { Eixo 1: comparação direta de } \\
\text { superfícies por meio da } \\
\text { inclusão. }\end{array}$ & $\begin{array}{l}\text { Perceber que: } \\
\text { - dados dois quadrados, o que tem a maior área é aquele que } \\
\text { tem o maior lado. } \\
\text { - dados dois polígonos regulares de mesmo número de } \\
\text { lados, tem a maior área aquele que tem o maior lado. }\end{array}$ \\
\hline 5.1 & $\begin{array}{l}\text { Eixo 1: comparação indireta de } \\
\text { superfícies por recorte e } \\
\text { colagem. }\end{array}$ & $\begin{array}{l}\text { Instrumentalizar os alunos para resolverem o problema de } \\
\text { transformar um quadrado em um retângulo de mesma área. } \\
\text { Levar o aluno a perceber que, quando decompomos uma } \\
\text { figura e reorganizamos as partes sem superposição, a figura } \\
\text { resultante tem a mesma área da primeira e essa área é igual } \\
\text { à soma das áreas das partes }\end{array}$ \\
\hline 5.2 & $\begin{array}{l}\text { Eixo 1: comparação indireta de } \\
\text { superfícies por recorte e } \\
\text { colagem. }\end{array}$ & $\begin{array}{l}\text { Levar os alunos a perceberem que, quando decompomos } \\
\text { uma figura e reorganizamos as partes sem superposição, a } \\
\text { figura resultante tem a mesma área da primeira e essa área é } \\
\text { igual à soma das áreas das partes. Transformar um retângulo } \\
\text { em quadrado de mesma área. Transformar o quadrado em } \\
\text { retângulo de mesma área. }\end{array}$ \\
\hline 6 & $\begin{array}{l}\text { Eixo 1: comparação indireta de } \\
\text { superfícies por recorte e } \\
\text { colagem. }\end{array}$ & $\begin{array}{l}\text { Perceber, por recorte e colagem, que figuras diferentes } \\
\text { podem ter a mesma área. } \\
\text { Rever os conhecimentos trabalhados nas atividades } \\
\text { anteriores. }\end{array}$ \\
\hline 7 & $\begin{array}{l}\text { Eixo 1: comparação indireta de } \\
\text { superfícies por recorte e } \\
\text { colagem. }\end{array}$ & $\begin{array}{l}\text { Identificar o quadrado e seus atributos. Perceber que a área } \\
\text { de um quadrado é igual ao dobro da área do triângulo que se } \\
\text { obtém cortando o quadrado ao longo de uma das suas } \\
\text { diagonais. } \\
\text { Perceber que é possível decompor o quadrado em dois } \\
\text { retângulos de mesma área e que é possível construir um } \\
\text { quadrado que tenha a metade da área de um quadrado dado. }\end{array}$ \\
\hline 8 & $\begin{array}{l}\text { Eixo 1: comparação indireta de } \\
\text { superfícies por recorte e } \\
\text { colagem. }\end{array}$ & $\begin{array}{l}\text { Resolver o problema da duplicação do quadrado. } \\
\text { Reconhecer que a área do quadrado construído sobre a } \\
\text { diagonal de um quadrado é o dobro da área do quadrado } \\
\text { dado. }\end{array}$ \\
\hline 9 & $\begin{array}{l}\text { Eixo 1: comparação indireta de } \\
\text { superfícies por recorte e } \\
\text { colagem. }\end{array}$ & $\begin{array}{l}\text { Trabalhar com a duplicação do quadrado. Construir um } \\
\text { quadrado igual a um triângulo isósceles dado. Verificar a } \\
\text { conservação de área na transformação do triângulo isósceles } \\
\text { em quadrado. }\end{array}$ \\
\hline
\end{tabular}




\begin{tabular}{|c|c|c|}
\hline Atividade & Eixo & Objetivo \\
\hline 10.1 & $\begin{array}{l}\text { Eixo 1: comparação indireta de } \\
\text { superfícies por recorte e } \\
\text { colagem. }\end{array}$ & Identificar formas geométricas. Comparar as áreas. \\
\hline 10.2 & $\begin{array}{l}\text { Eixo 1: comparação indireta de } \\
\text { superfícies por recorte e } \\
\text { colagem. }\end{array}$ & $\begin{array}{l}\text { Perceber que a área de uma figura não muda, mas sua } \\
\text { medida depende da unidade de medida escolhida. } \\
\text { Transformar uma superfície não pavimentada em } \\
\text { pavimentada. Calcular área por pavimentação tendo uma } \\
\text { unidade de medida definida. }\end{array}$ \\
\hline 10.3 & $\begin{array}{l}\text { Eixo 1: comparação indireta de } \\
\text { superfícies por recorte e } \\
\text { colagem. } \\
\text { Eixo 3: apontar as diferenças } \\
\text { entre comprimentos e área. }\end{array}$ & $\begin{array}{l}\text { Construir figuras com as peças do Tangram e comparar as } \\
\text { áreas. Trabalhar o conceito de perímetro. }\end{array}$ \\
\hline 11 & $\begin{array}{l}\text { Eixo 1: comparação indireta de } \\
\text { superfícies por recorte e } \\
\text { colagem. }\end{array}$ & $\begin{array}{l}\text { Evidenciar a natureza de uma unidade quadrada de área. } \\
\text { Calcular a área da figura utilizando como unidade o } \\
\text { quadrado. Escolher uma subunidade do quadrado para } \\
\text { medir a área. } \\
\text { Calcular a área de cada figura, adotando, como unidade de } \\
\text { medida, o quadrado da malha na qual ela está desenhada. }\end{array}$ \\
\hline 12 & $\begin{array}{l}\text { Eixo 2: estender a aplicação de } \\
\text { medida às áreas de superfícies } \\
\text { que não podem ser recobertas } \\
\text { por quadrados de área unitária. }\end{array}$ & $\begin{array}{l}\text { Por recorte e colagem, transformar uma superfície não } \\
\text { pavimentada em superfície pavimentada. }\end{array}$ \\
\hline 13.1 & $\begin{array}{l}\text { Eixo 1: comparação indireta de } \\
\text { superfícies por recorte e } \\
\text { colagem . } \\
\text { Eixo 2: estender a aplicação de } \\
\text { medida às áreas de superfícies } \\
\text { que não podem ser recobertas } \\
\text { por quadrados de área unitária. }\end{array}$ & $\begin{array}{l}\text { Trabalhar com a unidade quadrada. Construir, no geoplano, } \\
\text { polígonos cujo perímetro é dado. Comparar as áreas. }\end{array}$ \\
\hline 13.2 & $\begin{array}{l}\text { Eixo 3: apontar as diferenças } \\
\text { entre comprimentos e área. }\end{array}$ & $\begin{array}{l}\text { Perceber que polígonos de mesmo perímetro podem ter } \\
\text { áreas iguais ou diferentes. Entender que a medida do } \\
\text { perímetro não tem relação com a medida da área. A unidade } \\
\text { utilizada, para a medida do perímetro, é a distância entre } \\
\text { dois pregos, e não a diagonal do quadrado formado por eles. }\end{array}$ \\
\hline 13.3 & $\begin{array}{l}\text { Eixo 3: apontar as diferenças } \\
\text { entre comprimentos e área. }\end{array}$ & Identificar área e perímetro de figuras não convexas. \\
\hline 13.4 & $\begin{array}{l}\text { Eixo 2: estender a aplicação de } \\
\text { medida às áreas de superfícies } \\
\text { que não podem ser recobertas } \\
\text { por quadrados de área unitária. }\end{array}$ & Consolidar os conceitos de área. \\
\hline 14 & $\begin{array}{l}\text { Eixo 2: estender a aplicação de } \\
\text { medida às áreas de superfícies } \\
\text { que não podem ser recobertas } \\
\text { por quadrados de área unitária. }\end{array}$ & $\begin{array}{l}\text { Promover situações que provoquem no aluno procedimentos } \\
\text { para a medição de área para além da contagem de } \\
\text { quadradinhos; transformar uma superfície não pavimentada } \\
\text { em superfície pavimentada; tomar a decisão de fazer uma } \\
\text { contagem por aproximação. Verificar quais procedimentos } \\
\text { foram adotados pelos alunos. }\end{array}$ \\
\hline 15 & Eixos 1,2 e 3 & $\begin{array}{l}\text { Compreender que a área de um quadrado é uma unidade de } \\
\text { medida e essa unidade varia de acordo com a medida do } \\
\text { lado do quadrado. Compreender o metro quadrado como } \\
\text { unidade padrão. Analisar algumas relações entre as } \\
\text { unidades de medidas do sistema métrico decimal. }\end{array}$ \\
\hline
\end{tabular}

Nota: (*) Figura, neste trabalho, é uma superfície limitada e fechada contida no plano.

Após a elaboração das atividades, iniciamos a fase da experimentação, que consistiu no desenvolvimento das atividades em sala de aula, visando responder aos 
objetivos da pesquisa. Para Machado (2002), a experimentação tem início no momento em que se dá o contato com a população de alunos sujeitos da investigação e compreende a explicitação dos objetivos e condições de realização da pesquisa aos alunos, o estabelecimento do contrato didático, a aplicação da sequência e, finalmente, o registro das observações realizadas durante a pesquisa.

Essa fase ocorreu em 23 encontros de duas aulas, algumas vezes havendo necessidade de mais tempo, pois os alunos queriam pintar as figuras e optamos por aguardar. Inicialmente, combinamos um encontro por semana, mas houve semanas nas quais foram necessários dois encontros, tempo suficiente para trabalhar todas as atividades previstas. As professoras preferiram iniciar a implementação no terceiro bimestre. Esse era o período para o qual estava previsto o trabalho com o conteúdo objeto desta pesquisa.

As atividades foram aplicadas em sala de aula pelas respectivas professoras colaboradoras, com a nossa participação, também realizamos as observações e os registros para composição do caderno de campo, juntamente com as produções e depoimentos dos alunos participantes. No entanto, realizamos medições na implementação da sequência quando julgamos necessárias ou quando solicitadas pela professora.

Ao término de cada aplicação realizávamos a análise dos procedimentos de resolução e das representações dos alunos imersos na resolução das atividades. Durante a aplicação da atividade, ao analisarmos os invariantes operatórios produzidos pelos alunos inseridos nas situações de contexto histórico do conceito de área e sua medida, apresentávamos outra situação para torná-los pertinentes, quando estes não eram. Podemos citar o seguinte teorema em ação utilizado: dois triângulos formam um quadrado, quando entregamos vários conjuntos de triângulos para os alunos formarem quadrados. Foi explicitado, também, outro teorema: dois triângulos retângulos formam um quadrado. Em seguida, entregamos triângulos retângulos, mas de tamanhos diferentes. Em seguida, novos teoremas, sistematizamos com a ajuda dos alunos: "dois triângulos retângulos isósceles de mesma área formam um quadrado". Quando somente na análise percebíamos os teoremas não pertinentes, organizávamos uma atividade para retomar o assunto no encontro seguinte.

Nas análises, verificamos as conceitualizações implícitas nas ações dos alunos, os procedimentos de resolução, os erros e os acertos cometidos nas resoluções das situações, uma vez que os invariantes operatórios não são verdadeiros ou falsos, pois o conhecimento em ação nos permite agir em determinada situação independente de ser apropriado, ou não, segundo um determinado critério científico. (Vergnaud, 1990). 
Ao final da aplicação da sequência, em sala, as professoras afirmaram que inicialmente ficaram apreensivas com a quantidade de conteúdo que faltava trabalhar; no entanto, ao longo da sequência, foram percebendo que muitos desses conteúdos estavam sendo trabalhados concomitantemente.

Em algumas atividades a história estava implícita, em outras, era trabalhada explicitamente. O planejamento da aplicação de cada atividade em sala de aula era constituído de uma seção denominada "um pouco da história da construção do conceito de área”. Essa seção tratava do contexto histórico que fundamentava a elaboração e o desenvolvimento em sala de tal atividade.

Apresentamos a seguir alguns elementos da história da construção do conceito de área que fundamentou de maneira geral todas as atividades.

\section{Um Pouco de História do Conceito de Área}

O conceito de área e sua medida foram produzidos historicamente pelo Homem em sua interação com o meio físico, social e político. Ao abordamos a história, no nosso trabalho, não temos por intenção trabalhar todos os conhecimentos de medidas constituídos pelos historiadores; nessa primeira atividade, queremos apresentar, de modo geral, conhecimentos que nos orientaram na elaboração das atividades e, quando possível, atermo-nos a fatos específicos relacionados à atividade em questão. Nossa preocupação é evidenciar fatos que nortearam a definição da estratégia metodológica adotada em nosso trabalho.

A origem e os primórdios da geometria são atribuídos ao Egito pelo historiador Herôdotos (trad. 1988), que viveu no séc. V a. C. A sociedade no antigo Egito era essencialmente agrícola, desenvolveu-se ao longo das margens do rio Nilo, sendo calculados os impostos pagos pelos proprietários de terras em função da quantidade de terra útil para plantio. Após a inundação anual do rio Nilo, havia a necessidade de recalcular os impostos, passando o dono do lote a pagar um tributo proporcional à porção restante. Assim, a geometria egípcia surge da necessidade de medir diferentes áreas de terra, de determinar o valor do imposto a ser pago e de calcular o volume de silos utilizados para armazenar grãos. A partir de Gillings (1972), a título de exemplo do cálculo de área por essa civilização, podemos citar o problema 49 do papiro de Rhind.

Outro exemplo de cálculo de área está em Nove Capítulos da Arte Matemática, um manual da matemática chinesa, que data de 200 a. C. Na dinastia Han (206 a. C a 220 d. C.), textos literários e científicos foram transcritos devido à destruição dos livros ocorrida 
na dinastia anterior, de maneira que os originais são anteriores a essa data, sendo, no entanto, difícil datá-los. Esse manual é composto por 246 problemas sobre questões de mensuração de campos, de agricultura, comércio, sociedades, engenharia, impostos, cálculos e equações, cada um dos seus nove capítulos tratando de um tema específico. $\mathrm{O}$ primeiro capítulo é chamado de Mensuração de Campo e traz exemplos práticos daqueles tempos em agrimensura, tamanhos dos campos, construção de aterros, valas e armazéns, ou seja, está intimamente ligado com as necessidades do dia a dia daquela época.

Podemos citar também os babilônios, do período entre 2000 a 1600 a. C., que podiam obter áreas de campos irregulares, dividindo-os em triângulos retângulos, trapézios e retângulos, cujas áreas sabiam calcular; no entanto, a geometria era tratada de forma algébrica (Eves, 2004).

A civilização indiana, segundo Amma (1979), estava envolvida com métodos para transformar uma figura geométrica em outra, mais especificamente o quadrado em outra figura geométrica equivalente, ao que tudo indica, por meio de decomposição e composição. Segundo os teóricos, os Sulbasutras (753 a. C) são os mais importantes documentos escritos que permitem compreender os processos matemáticos utilizados nas construções de templos pelos indianos. Sulbasutras significa regras de corda e neles encontramos, como unidade de medida de área, a "purusha quadrado", derivada da unidade de comprimento "purusha", que significa a altura de um homem com os braços levantados. Assim como os egípcios, os indianos utilizavam homens conhecidos na época como estiradores de corda para realizar as medições. (Amma, 1979; Sarasvati, 1987). Gaspar (2004) refere-se à dimensão social da matemática e ao papel dos Subakaras, homens responsáveis pela construção dos altares indianos. Para Sarasvati (1987, p. 105), a construção dos altares exigia certos conhecimentos matemáticos: "Uma olhada nos diferentes altares é suficiente para mostrar que tudo isto não poderia ser realizado sem uma certa quantidade de conhecimento geométrico. Quadrados tinham de ser encontrados, os quais podiam ser iguais à soma de dois ou mais quadrados dados, ou iguais à diferença de dois quadrados dados; retângulos deviam ser transformados em quadrados e quadrados em retângulos; triângulos tinham de ser construídos iguais a quadrados ou retângulos dados; e assim por diante. A última tarefa, e não a menos importante foi o de encontrar um círculo, na zona em que pode ser igual, tanto quanto possível que a de um quadrado dado".

Então, o processo de comparar superfícies por recorte e colagem nos remete aos procedimentos utilizados por diferentes civilizações da Antiguidade - Egípcia, Babilônica, Indiana, Chinesa e Grega, na resolução de problemas envolvendo área. Os problemas mais 
comuns de medição baseados nos volumes de sólidos e áreas das figuras planas, em sua maior parte, eram calculados corretamente. Áreas de retângulos, triângulos e trapézios isósceles foram obtidas corretamente, provavelmente por um processo de "decomposição e composição", semelhantes aos encontrados nas geometrias indiana e chinesa. (Joseph, 2000, p. 82).

Segundo Boyer (1996), no Papiro de Ahmes existem problemas que utilizam o cálculo da medida de área com o uso de composição e decomposição de figuras. Nos textos indianos, datados do século $\mathrm{V}$ ao século IX a. C., há vários problemas que solicitam transformar uma figura em outra de mesma área. Os indianos utilizavam um procedimento equivalente ao uso de "régua e compasso" para decompor a figura e construir outra equivalente em área a ela. Algumas dessas transformações podem sugerir procedimentos de recorte e colagem.

Para Hogben (1958), o método utilizado nos elementos de Euclides para determinar a área de polígonos envolve a decomposição em triângulos, levando à inferência de que também os gregos usavam esse princípio de composição e decomposição para determinarem a área de figuras. Eves (2004) comenta que os pitagóricos resolviam problemas de cálculo de área de uma figura plana transformando-a em outra figura plana cuja área era conhecida. A construção de um polígono de área igual a outro dado pode ser encontrada nas preposições 42, 44, 45 do Livro I e na preposição 14 do Livro II dos Elementos de Euclides.

A seguir, apresentamos uma das atividades da sequência desenvolvida na pesquisa e sua análise, para que o leitor tenha referência da aproximação da História da Matemática e da didática da matemática, uma vez que a história que trabalha com fatos já ocorridos foi o contexto das situações e as teorias da didática nos orientaram a compreender a construção do conhecimento pelo sujeito que aprende.

\section{Atividade 9 - Transformar um Quadrado em Triângulo Isósceles de Mesma Área por Recorte e Colagem}

\section{(1) Um pouco de história do conceito de área}

$\mathrm{Na}$ civilização indiana a transformação de um quadrado em um triângulo isósceles era utilizada na construção do Praugacit, altar em forma de triângulo isósceles que tinha por finalidade destruir os inimigos. Todos Sulbasutras trazem a mesma orientação para a edificação desse altar: tomar um quadrado que tenha o dobro da área do quadrado; construir um quadrado "A" de área igual ao dobro de um quadrado "B", que por sua vez 
tem a área desejada para o altar a ser edificado; nesse quadrado devem-se desenhar linhas a partir do ponto médio do lado leste para os cantos inferiores (vértice do lado oposto) e, então, o triângulo isósceles obtido tem área igual à metade da área o quadrado "A" $\mathrm{e}$, portanto, igual a área do quadrado "B". (Amma, 1979).

Entre todas as transformações de uma figura em outra de mesma área, escolhemos a do quadrado em triângulo isósceles, pelo fato de a mesma permitir aplicar o conhecimento já adquirido da duplicação do quadrado. Para isso, optamos por trabalhar com a história explícita nessa atividade, orientando a resolução por etapas.

\section{(2) Objetivo}

Trabalhar com a duplicação do quadrado. Construir um quadrado igual em área a um triângulo isósceles dado. Verificar a conservação de área na transformação do triângulo isósceles em quadrado.

\section{(3) Material: Quadrados, sendo um o dobro da área do outro; tesoura e cola.}

\section{(4) Procedimento}

\section{(I) Contar aos alunos uma história que faça referência aos Sulbasultras}

Os Sulbasutras são manuais, livros que contêm instruções de caráter religioso para a construção de altares. A palavra Sulbasutra deriva das palavras "sulba" e "sutra", que significam "regras de corda".

Três dos Sulbasutras mais importantes do ponto de vista matemático, compostos em versos, foram os compilados por três matemáticos indianos: Baudhayana, Apastamba e Katyayana. Sabe-se que o mais importante desses textos é o de Baudhayana, datado de 800 a. C a 600 a. C; os outros foram, provavelmente, reunidos dois séculos depois.

As instruções encontradas nos Sulbasutras eram usadas para construir figuras de uma área dada, como triângulos, quadrados, retângulos, trapézios, círculos, semicírculos, e também figuras com área igual à de outras figuras. Por exemplo, para transformar um quadrado em um triângulo isósceles, com a mesma área, Baudhayana utilizou o seguinte método:

(a) Primeiro constrói-se um quadrado com o dobro da área do quadrado inicial.

(b) Em seguida, une-se o ponto médio de um dos lados obtidos a cada um dos vértices opostos a esse lado. Assim, era obtido o triângulo isósceles de mesma área do quadrado dado (Amma, 1979; Sarasvati, 1987). 
(II) Propor, então, o desafio: por recorte e colagem, verificar se o método de

\section{Baudhayana está correto}

Iniciar a medição para a construção. Convidar os alunos para a verificação proposta. Entregar a cada aluno um par de quadrados e afirmar: "Você recebeu dois quadrados, sendo que um tem o dobro da área do outro. Deve-se verificar se a relação entre as áreas dos quadrados realmente está correta e, em seguida, pelo método utilizado por Baudhayana, construir um triângulo isósceles igual em área ao quadrado. Por fím, transformar o triângulo isósceles em um quadrado de mesma área”.

\section{(5) Análise da atividade}

Quanto à verificação se a área de um dos quadrados dado tem o dobro da área do outro, foram apresentadas respostas semelhantes a estas:

"É verdadeira porque a diagonal do quadrado menor é do mesmo tamanho do lado do quadrado maior".

"Está correta porque o quadrado pequeno mede 2 triângulos e o grande mede 4 triângulos".

"Está correta, sei por que dobrei o quadrado vermelho (maior) em oito triângulos e medi e ficou igual ao triângulo azul (menor)".

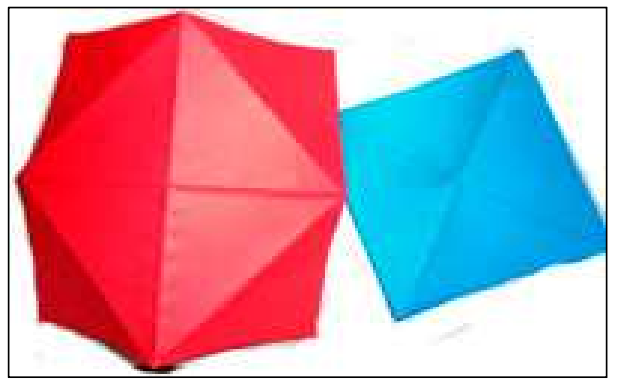

Figura 2 - Diagonal do quadrado é igual ao lado do quadrado maior

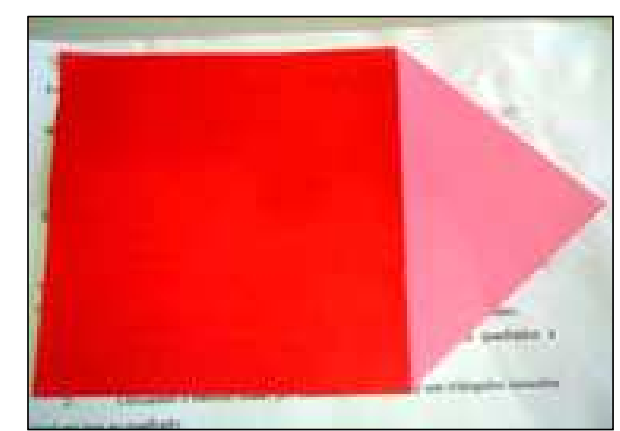

Figura 1 - Medindo o lado do quadrado com a diagonal do quadrado

"É porque quadrado maior tem oito triângulos e o menor só quatro triângulos".

"Eu dobrei na diagonal dos quadradinhos do quadrado grande e deu oito triângulos, $o$ quadrado pequeno tem 4 triângulos".

Os alunos resolveram a questão sem nenhuma dificuldade. Nós esperávamos que eles lembrassem a atividade da duplicação do quadrado e respondessem algo semelhante à primeira resposta, no entanto aquela foi a resposta que menos foi apresentada. Chamou-nos a atenção que eles trabalharam mais com o procedimento da atividade do que com o resultado, e se lembraram dos procedimentos para reduzir a área à metade. Então, tomaram 
o quadrado de maior área e dobraram de modo a encontrarem dois quadrados de mesma área, os quais, por sua vez, eram iguais à área do quadrado dado.

Questão 1 - Utilizando o método usado por Baudhayana para construir um triângulo isósceles igual em área ao quadrado

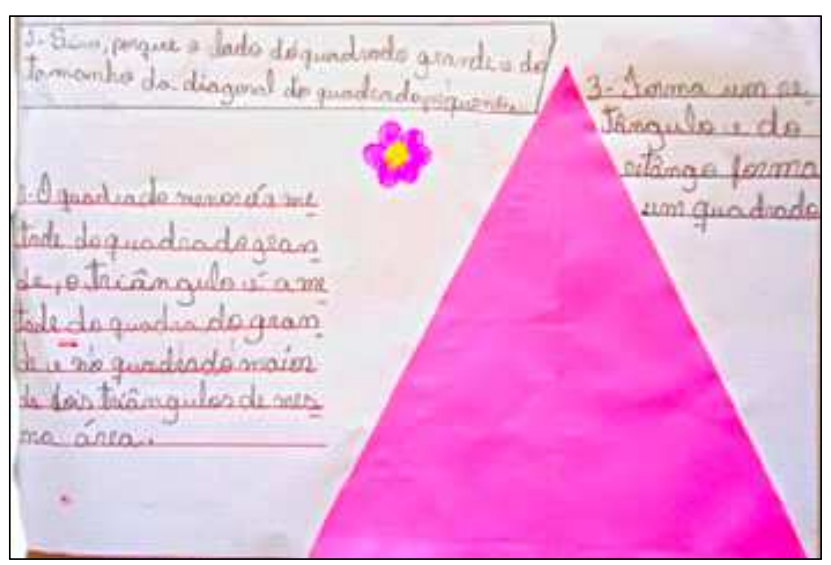

Figura 3 - Representação verbal escrita

"No quadrado maior fizemos um triângulo isósceles com os outros triângulos formamos um retângulo de mesma área do triângulo isósceles".

"Eu cortei formei um triângulo isósceles e formei com ele um quadrado".

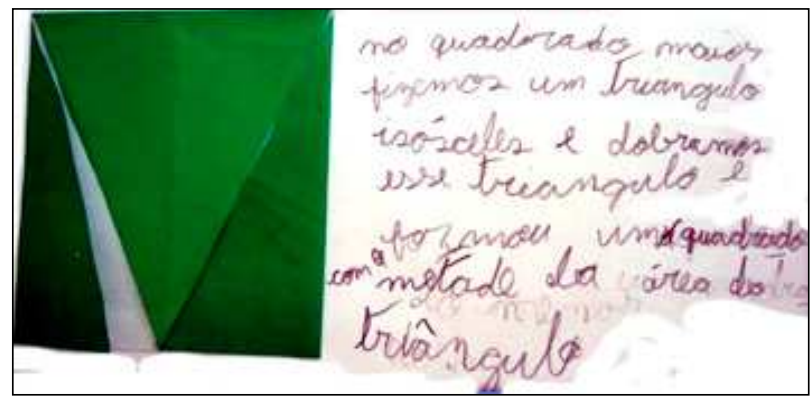

Figura 5 - Estabelecimento entre as medidas das áreas
"Eu pequei o quadrado com o dobro da área, dobrei e encontrei o ponto médio, formei o triângulo, cortei deu três triângulos, com os dois menores eu formei um triângulo. Fiquei com dois triângulos isósceles".

"Eu dobrei e encontrei o ponto médio e a partir dele eu passei linhas e formei um triângulo e depois eu recortei e com as partes que sobraram eu formei outro triângulo".

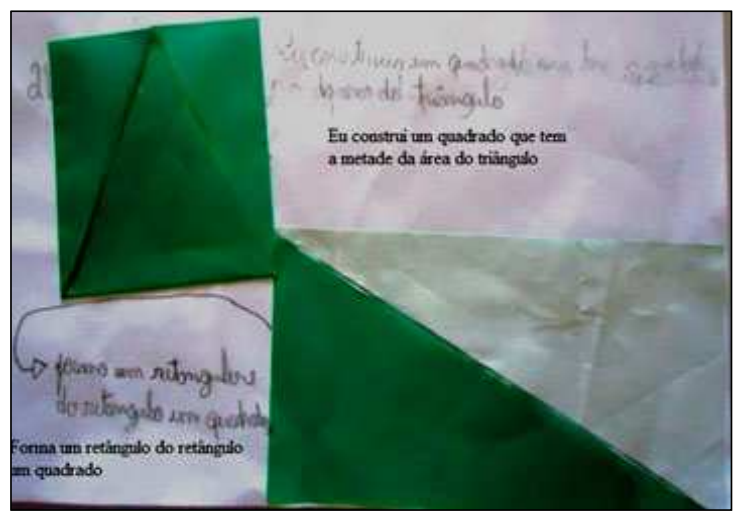

Figura 4 - Construção do triângulo isósceles

Todos os alunos que colaram o triângulo isósceles na folha escreveram algo semelhante a: "eu virei as três pontas do triângulo e formou um quadrado. Esse quadrado tem a metade da área do triângulo". Provavelmente, alguns fizeram $e$ os demais imitaram $o$ procedimento.

É importante enfatizar que eles perceberam que o triângulo poderia ser transformado em um quadrado, mas as áreas não seriam iguais; a relação estabelecida entre as medidas das áreas estava correta. Em seguida, refletimos com os alunos que a área 
daquele triângulo deveria ser igual à do quadrado menor, pois havíamos construído dois triângulos isósceles de áreas iguais, então eles mediram os dois triângulos.

Questão 2 - Transformar o triângulo isósceles construído em um quadrado de mesma área

Os alunos pegaram os dois triângulos retângulos e formaram um retângulo e, em seguida, um quadrado. No entanto, muitos não realizaram a última transformação. Chegavam até à construção do retângulo e escreviam: "agora é só transformar em quadrado", como se transformar o retângulo em quadrado fosse uma tarefa corriqueira, de conhecimento de todos e, assim, estava provado que o triângulo isósceles poderia ser transformado em um quadrado de mesma área. Eles se remetiam a um conhecimento adquirido anteriormente, especificamente, na Atividade 5.

Trabalharam com a decomposição do retângulo em triângulos para formar o quadrado, tendo um retângulo cujo lado era o dobro do outro.

Chamamos, mais uma vez a atenção a essa particularidade do retângulo para o qual o procedimento permitia realizar a transformação.

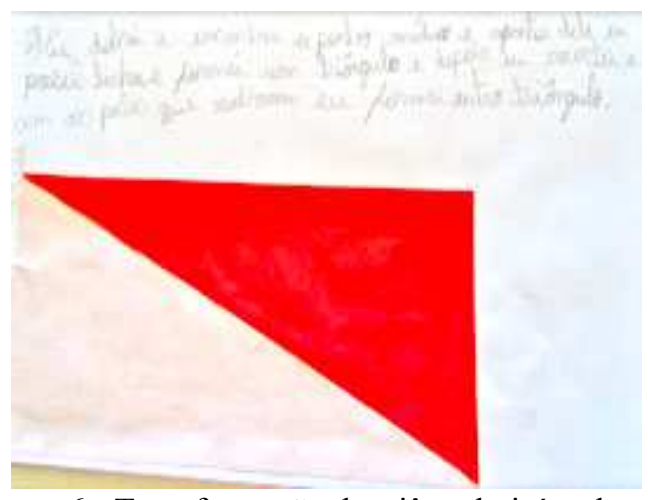

Figura 6 - Transformação do triângulo isósceles em retângulo

As respostas dadas assemelham-se a: "Forma um retângulo cortando o triângulo ao meio e do retângulo forma-se um quadrado”.

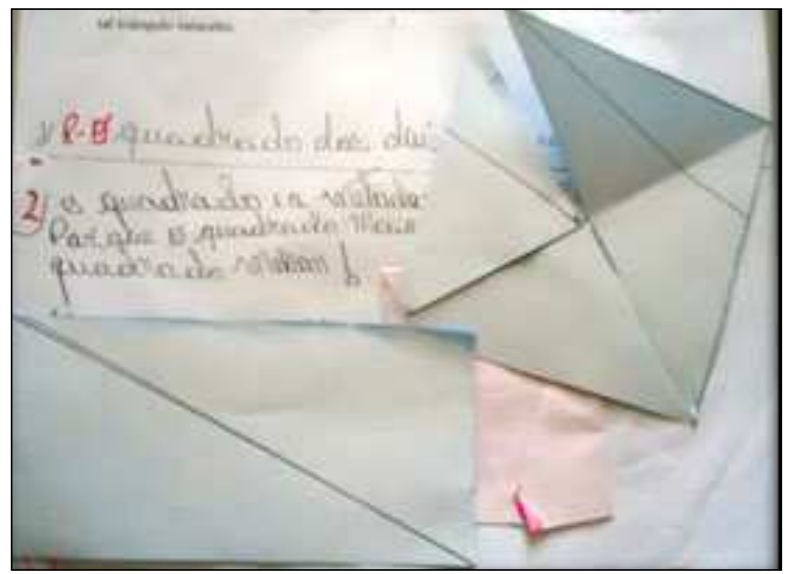

Figura 7 - Formação do retângulo cortando o triângulo ao meio
"Com o triângulo isósceles forma dois triângulos que formam o retângulo. Marca o ponto médio no lado maior do retângulo e desenha outro triângulo, recorta formando três triângulos junta os três triângulos formando um quadrado". "Para fazer o molde eu cortei o quadrado de área maior ao meio. Ficou um retângulo, eu dobrei ao meio formou dois quadrados iguais eu marquei a diagonal de cada quadrado, ficou um triângulo, eu cortei deu um triângulo grande e dois pequenos, depois juntei e formou o quadrado". 
Os alunos deste grupo, ao desenharem as linhas para cortarem, perceberam que dois triângulos retângulos formam um retângulo, então bastava pegar um quadrado, de mesma área, e cortar o meio formando dois retângulos. Esse era o "molde".

Optaram por trabalhar com o molde por terem dificuldades em formar três triângulos a partir dos dois triângulos.

Importante ressaltar que a dificuldade não era conceitual, e sim compor o triângulo como o da Figura 8, obtida a partir do retângulo, que por sua vez, estava composto por dois triângulos retângulos.

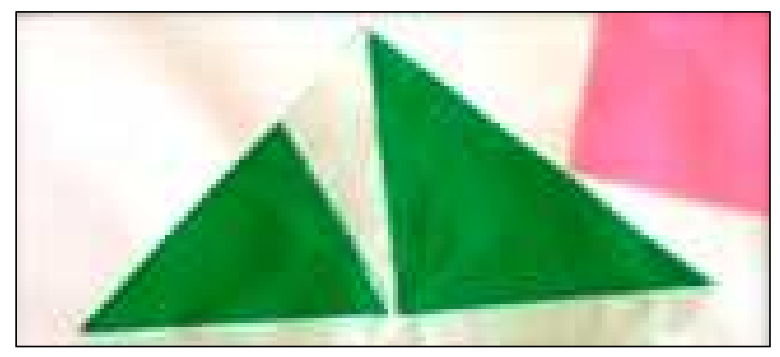

Figura 8 - Construção utilizando molde

A dificuldade não era cortar os triângulos, mas sim juntar as partes para formar o quadrado como a representação da Figura 9.

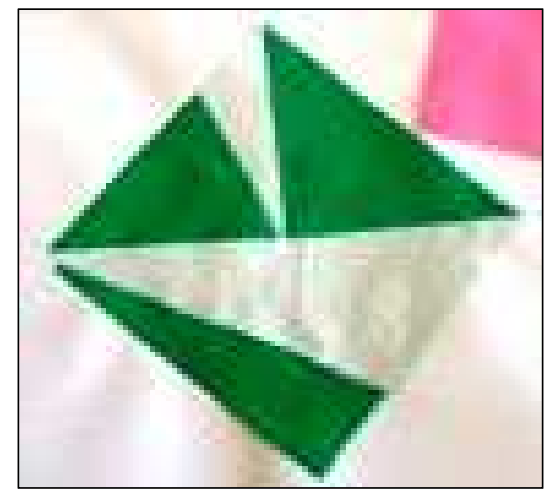

Figura 9 - Quadrado
"Eu cortei o triângulo isósceles ao meio, virei e ele formou um retângulo que eu cortei em triângulos arrumei em um quadrado".

Nesta resposta, o aluno enfatizou os movimentos de rotação e translação dos triângulos.

Os alunos que transformaram o retângulo tiveram dificuldades em trabalhar com as partes na recomposição do quadrado, pelo fato de o retângulo estar dividido em dois triângulos. Então, um aluno perguntou se poderia fazer um modelo, já que aquele procedimento havia sido utilizado em atividade anterior. Com o modelo, os alunos acharam mais fácil, mas alguns ainda preferiram trabalhar montando as partes. Como exemplo, citamos um que teve dificuldade em escrever com detalhes todos os procedimentos e perguntou se poderia fazer tudo com colagem. Entregamos a ele uma folha em branco e quadrados. 
Depois de pronto, pedimos para que ele explicasse à turma o que havia feito e, enquanto ele explicava, a professora escrevia no quadro. $\mathrm{O}$ procedimento do aluno por meio de recorte e colagem está representado na Figura 10. Utilizamos sua colagem para discutir passo a passo com a turma e depois a apresentamos na turma da professora Vitória.

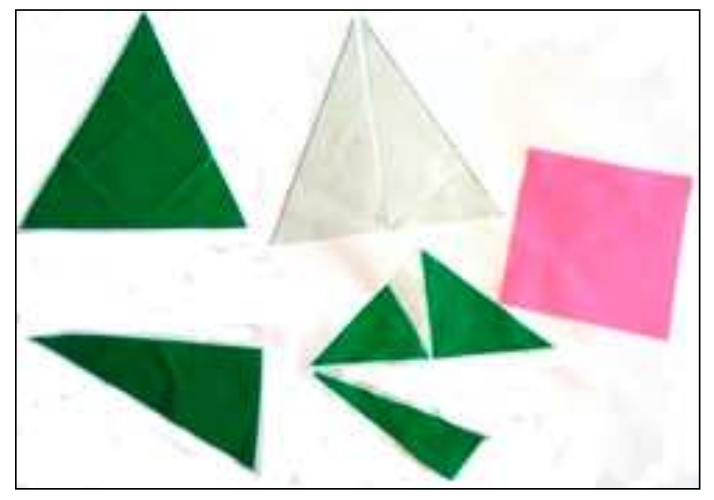

Figura 10 - Etapas da construção do triângulo isósceles

Conceitos em ação

- Triângulo isósceles tem dois lados iguais.

- Triângulo retângulo tem um ângulo de noventa graus.

- Ponto médio de um segmento de reta divide o segmento em dois de mesma medida.

Teoremas em ação

- A área do quadrado pode ser transformada em uma soma de áreas de triângulos iguais.

- Dividindo o triângulo isósceles ao meio, formam-se dois triângulos retângulos.

- Um quadrado pode ser transformado em dois quadrados de mesma área.

- O triângulo pode ser usado como unidade de medida de área.

- A medida de área é um número de determinada área, no caso, um triângulo.

- Para comparar igualdade entre área, a unidade de medida deve ser a mesma.

- Na comparação entre medidas de área, o dobro da unidade garante-nos o dobro da medida da área.

- Sabendo que uma unidade de medida de área é o dobro ou a metade de outra unidade de medida e a medida da área de uma grandeza em relação a uma delas, para saber a medida da área desta grandeza na outra unidade é suficiente multiplicar ou dividir a medida conhecida por dois.

- Em um quadrado x que tenha o seu lado igual à diagonal de um quadrado $\mathrm{y}$, podemos dizer que a área do quadrado x é igual ao dobro da área do quadrado y.

Os teoremas em ação explicitados e os procedimentos de resolução nos permitiram perceber que os alunos compreenderam a mudança do estatuto da figura e produziram 
conclusões, ou seja, observamos que teoremas em ação, mobilizados em atividades anteriores, foram associados às tomadas de decisão na resolução da atividade.

$\mathrm{Na}$ resolução dessa atividade, mais uma vez, os alunos vivenciaram as especificidades da apreensão operatória e trabalharam a relação parte-todo da figura por meio da decomposição e composição. Ao reconstruírem o quadrado, a partir do triângulo isósceles, reconfiguraram o quadrado por meio da visualização e realizaram deslocamentos de rotação e translação na construção do quadrado. (Duval, 1994).

Consideramos que os alunos evidenciaram compreender que uma figura plana pode ser decomposta e composta em outra de mesma medida de área e, assim, que figuras diferentes podem ter áreas iguais. Logo, a medida de área não está condicionada à forma da figura, de acordo com as pontuações de Vergnaud (1990, p. 52): “O saber se forma a

partir de problemas para resolver, quer dizer, de situações para dominar. [...] Por 'problema' é preciso entender, no sentido amplo que lhe atribui o psicólogo, toda situação na qual é preciso descobrir relações, desenvolver atividades de exploração, de hipótese e de verificação, para produzir uma solução.”.

Destacamos outra consideração: as concepções e crenças dos alunos em relação à Matemática, aos conceitos matemáticos e ao autoconceito como aprendizes de Matemática. A percepção das mesmas não só nessa atividade, como também ao longo de toda a sequência, apontou-nos caminhos para o trabalho em classe.

\section{Reações Afetivas ao Longo das Atividades}

Verificamos ao longo do trabalho que atividades fundamentadas na História da Matemática podem provocar no educando a explicitação de suas razões, emoções e ações, com relação a seus sentimentos, como aprendiz de matemática, e a sua capacidade de recriar conceitos, apropriando-se do mesmo, de acordo com sua vivência com a matemática. Acreditamos que os alunos passaram a perceber que o que conhecemos como matemática foi e é uma construção humana de avanços processuais.

Por meio da sequência de atividades, os estudantes foram capazes de comunicar seus conhecimentos e suas dificuldades ao grupo. Trabalhar com História da Matemática, pela investigação em sala de aula, foi, a nosso ver, tornar a aula criativa, na medida em que possibilitou a produção de um novo valor na aprendizagem e no desenvolvimento do aluno, pois o educando teve a possibilidade de desenvolver a oralidade e aquele que sentia dificuldade em se expor teve oportunidade de vencer seu silêncio. $\mathrm{O}$ ambiente tornou-se favorável para o desenvolvimento do raciocínio lógico, da capacidade de induzir, deduzir e 
inferir, para o desenvolvimento do senso crítico, da imaginação e da criatividade do aluno, para a manifestação da curiosidade da criança em relação ao tema e para a manifestação de suas propriedades artísticas.

Como os ritmos de aprendizagem são diferentes para as pessoas, percebemos que alguns alunos precisaram de mais tempo do que outros, mas para cada um foi um avanço relevante no movimento de muitas aprendizagens, entre elas a emocional. O tempo de produção e aprendizagem depende do "modus operandi", assim, como há nos grupos diferentes modos de produção matemática, temos, por consequência, tempos diferentes, e os que são mais rápidos, não necessariamente são mais inteligentes.

Pais (2002) afirma que o saber matemático se constituiu de noções objetivas, abstratas e gerais, no entanto não há como negar a intermediação da subjetividade e da particularidade na atividade humana de sua elaboração, uma vez que os sentidos subjetivos desenvolvidos na aprendizagem constituem, segundo González Rey (2006), verdadeiros sistemas motivacionais, que permitem aos alunos representarem o seu envolvimento afetivo com a atividade desenvolvida, isto é, a subjetividade, no contexto da aprendizagem, revela tendências na forma de pensar e agir no desenvolvimento da atividade pedagógica. Ainda, conforme González Rey (2006, p. 32): “As emoções que o sujeito vai desenvolver no processo de aprendizagem estão associadas não apenas com o que ele vivencia como resultado das experiências aplicadas no aprender, mas emoções que têm sua origem em sentidos subjetivos que trazem ao momento atual do aprender momentos de subjetivação produzidos em outros espaços e momentos da vida.".

Gómez Chacón (2003) se refere às crenças como "verdades" pessoais incontestáveis de cada um, derivadas da experiência ou fantasia que tem um forte componente avaliativo e afetivo. Para Vila e Callejo (2006), as crenças são um tipo de conhecimento subjetivo referente a um conteúdo com forte componente cognitivo que predomina sobre o afetivo.

Apontamos, pois, a História da Matemática, utilizada como recurso didático, como um espaço de: alegria, realização, descoberta do potencial de aprendizagem e de ver o mundo como uma obra em permanente construção.

Temos consciência de que a História da Matemática como metodologia de ensino ou como instrumento didático não pode dar conta de todas as dificuldades que o ensino da matemática tem enfrentado no mundo contemporâneo, no entanto constatamos que ela exerce importante papel no processo de ensino e aprendizagem. Assim, ela representa uma opção pedagógica de abordagem dos conteúdos, pois permite ao professor problematizar 
situações que tornam a aprendizagem significativa para o aluno, além de favorecer momentos de produções cognitivas nas quais podemos identificar e interpretar os procedimentos e a apropriação significativa do conhecimento matemático. Então, atividades com fundo histórico podem estimular a autoconfiança na capacidade de aprender matemática.

Com os estudos das teorias de Duval e Vergnaud, aprendemos a ficarmos alertas ao movimento do pensamento do aluno e do nosso. A pesquisa apontou que é mais fácil analisar a construção de um conceito pelo aluno quando ele erra, porque é possível identificar as diferentes interpretações que ele faz do objeto e as confusões com os símbolos análogos de um texto escrito em linguagem matemática. Quando ele aplica a regra corretamente, muitas vezes não modifica nada, então não há uma ação por meio da qual possamos perceber seus registros na construção do conceito.

Reiteramos, mais uma vez, que é esse um caminho da História da Matemática que podemos percorrer: trazer uma matemática viva. Viva porque explora e investiga o mundo real no tempo presente.

\section{Consideraçõs Finais}

Na pesquisa como um todo, verificamos que, ao longo das atividades, os estudantes foram identificando a área como grandeza, já que, para resolverem as situações dadas, utilizaram a visualização, a decomposição, a composição das figuras e das unidades e, nas tomadas de decisões, para resolução, não confundiram superfície com área, pois apreenderam que a área é uma grandeza associada à superfície. Os alunos também apresentaram estratégias que nos levaram a considerar que eles estavam dominando o conhecimento de que a decomposição e a reconfiguração da figura, sem perda nem acréscimo de partes, conserva a medida de área e, então, pode-se transformar a figura em outra figura cuja medida da área já era conhecida.

Os sujeitos calcularam a medida da área pela soma das áreas das subfiguras que preenchiam a figura dada. Adquiriram, de acordo com Duval (1994), por meio da apreensão perceptiva, a habilidade de interpretar figuras geométricas pela sobreposição das mesmas, conceitualizando que as figuras podem ter áreas diferentes ou iguais e que, ao compará-las, a que "cabe" dentro da outra tem área menor. Os alunos, também, evidenciaram que a compreensão de que a medida da área de uma superfície (uma figura) depende da unidade de medida que está sendo utilizada e que, na medida de área, o número está associado à grandeza, ou seja, a medição depende da unidade escolhida. Assim, a área 
não é igual a um número, pois esse pode mudar de acordo com a unidade escolhida para fazer a contagem.

Como já analisado por Duval (2003), nossos sujeitos também apresentaram, na resolução das atividades, a operação mereológica de reconfiguração na construção do raciocínio, levando-se em conta a sobreposição, e, tendo como filtros desse conhecimento, a ajuda entre pares, reconfiguração, a forma visualizada e desenhada no papel e caracterização de figuras diferentes formadas a partir das figuras que recebiam em cada atividade. Em outros termos, a grande maioria das atividades da sequência nos permitiu analisar as produções matemáticas em processo de reconhecimento de que, por meios de operações figurais, podemos transformar uma figura em outra de mesma área. Uma atividade na qual o aluno não precisava proceder a cálculos algébricos, pois utilizava as operações mereológicas de reconfiguração, as quais se apoiavam sobre a percepção.

Conforme Duval (2011), é preciso ter tomado consciência dos tipos de operações figurais e ter adquirido a mobilidade de focalização dimensional do olhar para reconhecer as múltiplas unidades figurais que se fundem no reconhecimento imediato de qualquer forma 2D. Pelos procedimentos de resolução adotados ao longo do trabalho, podemos dizer que as atividades ajudaram o aluno a tomar tal consciência.

Os estudantes também demonstraram compreender que para determinar a medida da área, devemos comparar essa área com a unidade de medida. No entanto, para isso, a medição não depende do recobrimento da figura utilizando uma quantidade finita de áreas unitárias da mesma forma da unidade dada. Se isso não for possível na figura dada, ele pode criar outros procedimentos de medida. Percebemos que os alunos não confundiram contorno com superfície, nem perímetro com área. Compreenderam que medir área é comparar duas áreas entre si, ou seja, verificar quantas vezes uma área tomada como unidade de medida cabe em outra área. Apresentaram a compreensão da relação entre o número e a unidade de medida ao afirmar que a área pode ser a mesma, mas ter medida de área diferente de acordo com a unidade de medida utilizada.

Constatamos ainda que a resolução de uma atividade apresentava a familiarização de procedimentos e de conhecimentos estudados em atividades anteriores da sequência, o que aponta o crescimento gradativo do aluno na significação do conceito de área e sua medida.

Assim, com base nas concepções históricas, as informações foram usadas na elaboração de atividades que provocaram ações de atividade no aluno, nas quais ele organizava o pensamento para a devida resolução, e, a partir de um esquema, ele construía 
novos esquemas. $\mathrm{O}$ aluno se apropriava dos conceitos elaborados e os reelaborava para dar conta de novas situações, realizando uma síntese dos conceitos anteriores de maneira racional e criativa. Isso também nos permite falar em construção de conceitos matemáticos pelo aluno a partir de conhecimentos fundamentados na História da Matemática.

Para esses estudantes, antes da participação na pesquisa, o mundo da matemática era platônico, sua concepção era de uma realidade matemática independente de nossa prática, de nossa linguagem, de nosso mundo.

O trabalho com as atividades fundamentadas na História da Matemática permitiu mostrar ao estudante que a matemática é para todos, apesar de requerer esforço, dedicação - se errar não pode desistir -, que é importante experimentar sempre, que as pessoas, as quais elaboraram um teorema, não o fizeram da noite para o dia e, muitas vezes, muitas pessoas pensaram naquele teorema e o melhoraram até ele estar na forma como o conhecemos hoje. Logo, os conhecimentos não estão prontos e nem instalados de maneira singular e simplória, mas são construídos num processo que envolve tempo, conhecimentos, contextos e pessoas.

É importante, também, tecer alguns comentários acerca do aspecto da linguagem verbal. O trabalho com a História da Matemática trouxe contribuições ao desenvolvimento da matemática como linguagem na elaboração do discurso argumentativo pelo aluno. Mencionamos, a título de exemplo, o questionamento de uma aluna: "os povos antigos transformavam tudo em quadrado para medir a área, mas os gregos dividiam as figuras em triângulos, dos triângulos em retângulos, os retângulos em quadrados. Então, por que a unidade de medida não é o triângulo? Por que nossa unidade é quadrática"? Como não aguardávamos por tal pergunta, não tínhamos a resposta elaborada. Ela continuou argumentando: "veja bem, se eu junto triângulos, tenho quadrado; se corto quadrados, posso ter triângulos; então, a unidade de medida deveria ser o triângulo". Resguardadas algumas questões conceituais que discutimos com o grupo, como a questão de os triângulos formarem quadrados, a argumentação era pertinente aos seus conhecimentos.

\section{Referências}

Amma, T. A. S. (1979). Geometry in Ancient and Medieval India. Índia: Motilal Banarsidass.

Boyer, R, C. B. (1996). História da Matemática (2a ed.). (E. F. Gomide, Trad.). São Paulo: Edgar Blücher.

Douady, R., \& Perrin-Glorian, M. (1989). Un processus d'apprentissage du concept d'aire de surface plane. Educational Studies in Mathematics, 20, 387-424. 
Duval, R. (1993). Registres de représentation sémiotique et fonctionnement cognitif de la pensée. Annales de Didactique et de Sciences Cognitives, Irem de Strasbourg, 5, $37-65$.

Duval, R. (1994). Les différents fonctionnememts d'une figure dans une demarche géométrique. Irem de Strasbourg, 17, 121-137.

Duval, R. (2003). Registros de representações semióticas e funcionamento cognitivo da compreensão em matemática. In Machado, S. D. A. (Org.). Aprendizagem em Matemática: registros de representação semiótica (pp. 11-33). Campinas: Papirus.

Duval, R. (2011). Ver e ensinar a matemática de outra forma: entrar no modo matemático de pensar os registros de representações semióticas (T. M. M. Campos, Org,) (M. A. Dias, Trad.). São Paulo: PROEM.

Eves, H. (2004). Introdução à história da matemática (H. H. Domingues, Trad.). Campinas: Unicamp.

Gaspar, M. T. J. (2004). Um estudo sobre áreas em um curso de formação de professores tomando como ponto de partida a história da matemática indiana no período dos Sulbasutras. RBHM, 4(8), 189-214.

Gillings, R. J. (1972). Mathematics in the Time of the Pharaohs. New York: Dover Publications Inc.

Gómez Chacón, I. M. (2003). Matemática emocional. Porto Alegre: Artmed.

González Rey, F. (2006). O sujeito que aprende: desafios do desenvolvimento do tema da aprendizagem na psicologia e na prática pedagógica. In Tacca, M. C. (Org.) Aprendizagem e trabalho pedagógico (pp. 29-44). Campinas: Alínea.

Herôdotos. (1988). História (2a ed.). (M. da G. Kury, Trad.). Brasília: Universidade de Brasília.

Hogben, L. (1958). Maravilhas da matemática: influência e função da matemática nos conhecimentos humanos (4a ed.). Rio de Janeiro: Globo.

Joseph, G. G. (2000). The Crest of the Peacock: non-european roots of mathematics (2a ed.). USA: Princeton University Press.

Machado, S. D. A. (2002). Engenharia Didática. In: introdução. (2a ed). (pp.197-208). São Paulo: EDUC, 2002.

Pais, L. C. (2002). Transposição didática. In Machado, S. D. A. Educação matemática: uma introdução. (2a ed). (pp. 11-48). São Paulo: EDUC.

Sarasvati, S. S. P. (1987). Geometry in ancient India. Índia: Govindran Hasanand.

Vergnaud, G. (1990). La théorie de champs conceptuels. Recherches en Didactique de Mathématiques, 10(2.3), 133-170.

Vergnaud, G. (1996). A teoria dos Campos Conceituais. In: BRUNNER, J. Didáctica das Matemáticas. Lisboa: Instituto Piaget, 1996. p. 155-191.

Vergnaud, G. (1998). A Comprehensive Theory of Representation for Mathematics Education. Journal of Mathematical Behavior, 17(2), 167-181.

Vergnaud, G. (2003). A gênese dos campos conceituais. In Grossi, E. P. (Org.). Por que ainda há quem não aprende? A teoria (pp. 21-64). Petrópolis: Vozes. 
Vila, A., \& Callejo, M. L. (2006). Matemática para aprender a pensar o papel das crenças na resolução de problemas (E. Rosa, Trad.). Porto Alegre: Artmed.

\section{Autores}

Edilene Simões Costa dos Santos

Doutorado em Educação em Ciências e Matemática pela Universidade de Brasília, mestrado na área de Educação (Ensino e Aprendizagem) pela Universidade Católica de

Brasília. Graduação em Ciências, Habilitação em Matemática pelo UniCeub/DF. Professora do Instituto de Matemática da UFMS e do Programa de Pós-graduação em Educação Matemática da UFMS. Integrante dos grupos de pesquisa Compasso/DF, GPHEME, GHEMAT. Mais informacões no Currículo Lattes: http://lattes.cnpq.br/4416986244015282. ORCID: https://orcid.org/0000-0002-0509-0098. E-mail: edilenesc@gmail.com.

\section{Cristiano Alberto Muniz}

Doutorado em Sciences de l'Education pela Université Paris Nord (1999). Pós-Doutor em Educação pela UnB (2015). Graduação em Bacharelado e Licenciatura em Matemática pela Universidade de Brasília (1982). Mestrado em Educação pela Universidade de Brasília (1992). Docente Associado Aposentado da Universidade de Brasília. Tem experiência na área de Matemática, com ênfase em Educação Matemática, atuando principalmente nos seguintes temas: educação matemática, educação matemática, aprendizagem matemática, aprendizagem matemática e formação do professor de matemática. Atualmente desenvolve jogos para aprendizagem matemática para crianças DI. Coordena projetos socio-educacionais junto à crianças em situação de risco social na Chapada dos Veadeiros/Goiás. Mais informacões no Currículo Lattes: http://lattes.cnpq.br/9878321982029909.

E-mail: cristianoamuniz@gmail.com

Maria Terezinha Jesus Gaspar

Doutorado em Educação Matemática pela Universidade Estadual Paulista Júlio de Mesquita Filho (2003). Mestrado em Matemática pelo Instituto Nacional de Matemática Pura e Aplicada (1980). Graduação em Matemática Bacharelado pela Universidade Federal da Bahia (1975). Atualmente é professora voluntária da Universidade de Brasília. Tem experiência na área de Matemática, com ênfase em Matemática, atuando principalmente nos seguintes temas: formação de professores, história da matemática, educação matemática, ensino médio e ensino fundamental e avaliação. Mais informacões no Currículo Lattes: http://lattes.cnpq.br/4364026635376610. E-mail: mtjg.gaspar@gmail.com 